doi:10.18575/msrs.sm.s.16.06 UDK: 616-089.168 (497.6 Republika Srpska) COBISS.RS-ID: 5698840

\section{Prevalencija intrahospitalnih infekcija na hirurškim klinikama Univerzitetskog kliničkog centra Republike Srpske}

\section{SAŽETAK}

Uvod. Intrahospitalne infekcije (IHI) predstavljaju opšti javnozdravstveni problem koji postoji u svim zdravstvenim sistemima i čije su posljedice vrlo značajne. Obaveza svih zdravstvenih sistema je unapređenje preventivnih mjera koje mogu da smanje učestalost ovih infekcija od 10\% do 70\%, pri čemu ključnu ulogu ima uspostavljanje funkcionalnog epidemiološkog nadzora nad $I H I$.

Cilj rada. Rad ima za cilj da, kroz izvođenje studije prevalencije, pokaže kolika je učestalost IHI na hirurškim klinikama Univerzitetskog kliničkog centra Republike Srpske (UKC RS), koje su njihove najznačajnije epidemiološke karakteristike, koji su najčešći uzročnici te kolika je njihova rezistencija na antibiotike.

Materijal i metode. $U$ procesu izrade rada korištena je standardizovana metodologija za izvođenje studije prevalencije IHI, uključujući i primjenu definicija infekcija, koja se koristi u Evropskoj uniji a koju je utvrdio Evropski centar za kontrolu bolesti. Studija je sprovedena u oktobru 2014. godine na hirurškim klinikama UKC RS, a uključeno je ukupno 196 pacijenata.

Rezultati. Prevalencija IHI na hirurškim klinikama UKC RS je iznosila 11,7\%. Najčešća lokalizacija IHI su infekcije operativnog mjesta (60,8\%). Najčešći uzročnici IHI su Acinetobacterspp., Enterococcusspp., Pseudomonasaeruginosai Staphylococcusaureus. Rezistencija na karbapeneme je zabilježena kod svih izolovanih sojeva Acinetobacter i 50\% izolovanih Pseudomonas, na meticilin kod 50\% Staphylococcusaureus, na vankomicin kod 50\% izolovanih Enterococcusspp., a na cefalosporine treće generacije kod 40\% Enterobacteriaceae.

Zaključak. Rezultati studije su pokazali da je prevalencija IHI na hirurškim klinikama UKC RS u okvirima prevalencije u zemljama u razvoju. Problemu IHI se mora posvetiti veća pažnja. Studije prevalencije bi mogle da budu metod izbora za nadzor nad IHI na nacionalnom nivou.

Ključne riječi: prevalencija, intrahospitalne infekcije, epidemiološki nadzor.

(Scr Med 2016:47:34-41)
Jela Aćimovíc,

SLaviš Kumarac," Nina Rodić Vukmiv, ${ }^{1,2}$ Ljubinka Božíc Majsforovic, ${ }^{p, g}$ Ljubica Bojanić

${ }^{1} J Z U$ Institut za javno zdravstvo Republike Srpske, Banja Luka, BiH ${ }^{2}$ Medicinskifakultet Banja Luka, Univerzitet u Banjoj Luci, BiH ${ }^{3}$ Univerzitetski klinički centar Republike Srpske

\section{Kontakt adresa:}

Jela Aćimović, Knežopoljska 19 Banja Luka 7800 o Banja Luka, BiH; E-mail: jela.acimovic@gmail.com Telefon: + 38765620512 Faks: + 38751491649

Rad primljen: 14.1.2016. Rad prihvaćen: 31.1.2016. 


\section{Uvod}

Intrahospitalna infekcija (IHI) je klinicki manifestna infekcija koja se javila kod pacijenta u bolnici ili u nekoj drugoj zdravstvenoj ustanowi, a koja nije bila prisutna niti je bila u inkubaciji u vrijeme prijema. Ovo uključıje i infekcije koje su stečene u bolnici, ali su se manifestovale nakon otpusta, kao i profesionalne infekcije kod osoblja zdravstvene ustanove. ${ }^{1}$

IHI predstavljaju opšti javnozdravstveni problem koji postoji u svim zdravstvenim sistemima, a praćene su vrlo značajnim posljedicama: produžavaju boravak u bolnici, uzrokuju češce ponovne hospitalizacije, povećavaju obolijevanje i smrtnost, mogu stvarati dugoročnu invalidnost, povećavaju rezistenciju na antibitike, predstavljaju ogromno dodatno finansijsko opterećenje za zdravstvene sisteme te stvaraju velike troskkowe za pacijente $\mathrm{i}$ njihowe porodice. ${ }^{2}$ S obzirom na to da IHI ugrožavaju pacijentovo pravo na sigurnost u bolničkoj ustanovi, oni imaju veliki etički značaji predstavljaju čest prednet sudskih sporova. ${ }^{3}$

IHI značajno utičı na obolijevanje i smrtnost u svim dijelowima svijeta. Učestalost IHI se razlikuje u razijenim i zemljama u razvoju, ali i u pojedinim bolnicama $\mathrm{i}$ пa pojedinim odjeljenjima. Njihowa prevalencija u razvijenim zemljama je u prosjeku 7,6\% (između 3,5\% i 12\%), dok je u zemljama u razwoju prosječno 10,2\% (od 5,7\% do $19,1 \%)^{4}$

Studija prevalencije, sprovedena od strane ECDC-a 2011. i 2012. godine u 947 bolnica šrom Evropske unije, pokazala je da je prosječna prevalencija IHI 6,0\%.5 U 183 bolnice iz više država SAD-a je 2011. godine sprovedena studija koja je pokazala da $4 \%$ hospitalizowanih pacijenata ima barem jednu IHI. ${ }^{\circ}$

Podaci iz zemalja u razvoju su oskudni, s obzirom da samo oko $15 \%$ ovih zemalja ina funkcionalan sistem epidemiolołkokg nadzora nad IHI.Više studija sprovedenih u zdravstvenim ustanovama zemalja sa ograničenim resursima pokazuju stope prevalencije veće nego u razijenim zenljama.?

Među klinički značajnim bakterijama koje najčešce uzrokuju IHI, ističu se Gram pozitivne multirezistentne patogene bakterije kao što sumeticilin-rezistentni Staphylococcusaureus (MRSA) i vankomicin-rezistentni Enterococcusspp. (VRE), Gram negativni sojevi Klebsiellapпeumoniae, Escherichia coli, Pseudomonasspp. i Acinetobacterbaumannii, koji produkuju prošireni spektar $\beta$-laktamaza (ESBL), kao i Clostridiumdifficile. ${ }^{\mathrm{B}}$ Incidencija owih infekcija kod hospitalizowanih pacijenata, kao i smrtnost i zdravstveni troškovi koje one prouzrokuju, su vrlo visoki. ${ }^{\mathrm{B}}$
Na hirır:̌̌kim odjeljenjima, IHI predstavljaju vrlo značajan problem, posebno kod pacijenata sa oslabljenim imuniteton. Većina studija pokazuje da su najučestalije IHI na ovim odjeljenjima infekcije operativnog mjesta. Svaka infekcija operativnog mjesta produžava hospitalizaciju za dodatnih 7-11 dana, dok dodatni trokkowi zavise od vrste operacije i tipa infektivnog uzročnika. Pacijenti sa infekcijom operativnog mjesta imaju 2-11 puta veći rizik od smrtnog ishoda, u poređenju sa operisanim pacijentima bez infekcije operativnog mjesta. ${ }^{9}$

Mnoge IHI su neizbježne zbog osnowne bolesti hospitalizovanog pacijenta, invazivnih dijagnostičkih i terapijskih procedura i potencijalno patogenih mikroorganizama endogene flore, koji mogu izazwati ozbiljne infekcije ako su normalni odbrambeni mehanizmi domaćina oslabljeni. ${ }^{10}$ Ipak, mnoge IHI mogu biti spriječene. Učestalost IHI se mjerama prevencije može smanjiti od minimalno $10 \%$ do maksimal no $70 \%$, zavisno od vrste zdravstvene ustanove, dizajna studije, postojećih stopa infekcije i vrste infekcije. ${ }^{10}$

Razvoj epidemiološkog nadzora nad IHI je neophodni prvi korak ka identifikovanju lokalnih problema i prioriteta te evaluaciji efikasnosti mjera za kontrohu infekcije. Nadzor, sam po sebi, predstavlja efikasan proces za smanjenje učestalosti IHI. ${ }^{1}$ Korištenje standardizovanih definicija je od ključnog značaja za pouzdanost nadzora nad IHI i predstavlja jedan od osnownih uslowa koji mora biti zadowoljen da bi bilo moguće poređenje podataka o IHI na lokalnom, nacionalnon i međunarodnom nivou. ${ }^{7}$

\section{Cilj rada}

Rad ima za cilj da, kroz izvođenje studije prevalencije, pokaže kolika je učestalost IHI na hirurškim klinikamaUniverzitetskog kliničkog centra Republike Srpske (UKC RS), koje su njiһove najznačajnije epidemiolozke karakteristike, koji su najčešći uzročnici te kolika je njihova rezistencija na antibiotike.

\section{Materijal i metode}

Studija je sprovedena u oktobru 2014. godine na hirurškim klinikama UKC RS, a uključeno je ukupno 196 pacijenata. Korištena je standardizowana metodologija za izwođenje studije prevalencije IHI, uključujući i primjenu definicija infekcija, koje se koriste u Evropskoj uniji a koje je utvrdio Evropski centar za kontrolu bolesti (ECDC). ${ }^{11}$

U prikupljanju podataka korišten je standardni ECDC protokol, baziran na pacijentu. Podaci su prikupljani kroz dva upitnika, Upitnik za zdravstvenu ustanovı (podaci o bolnici) i Epidemioloski upitnik (popunjen za svakog pacijenta koji je uključen u studiju, bez obzira da li ima infekciju ili ne). Epidemiološki upitnik uključıje op- 
ste podatke o pacijentu i podatke of faktorima rizika (hirurǩki zahvat po prijemu, NHSN ili ne-NHSN kategorija, McCabe skor, invazivne procedure: centralni ili periferni vaskularni kateter, urinarni kateter, intubacija). ${ }^{11}$

Informacije o infekciji kod pacijenta su prikupljane samo ukoliko je pacijent imao manifestnu infekciju povezanu sa boravkom u bolnici, u skladu sa ECDC definicijon IHI. Prema ovoj definiciji, IHI je infekcija koja se manifestovala treći dan od prijema u bolnicu ili kasnije, a zadovoljava definiciju slučaja na dan studije. I infekcije koje su se manifestovale u toku prva dva dana hospitalizacije se mogu smatrati intrahospitalnim ukoliko je pacijent otpušten iz bolnice za akutnu njegu u prethodnih 48 sati, odnosno u prethodnih 28 dana ako postoji Clostridium difficile infekcija, ili je prije početka simptoma upotrebljen relevantan invazivni uređaj. Infekcija operativnog mjesta koja se javila unutar 30 dana od operacije ako nije ugrađen implantat, ili unutar jedne godine ako je ugraden implantat, smatra se intrahospitalnom. ${ }^{11}$

Prema protokolu, prikupljaju se mikrobiološki rezultati dostupni na dan studije. Specificiraju se do tri izolowane vrste mikroorganizama. Određuje se osjetjivost na izabrani marker antimikrobne rezistencije, zavisno od uzročnika. Tako se za Staphylococcusaureus određuje rezistencija na oksacilin, za Enterococcusspp. se određuje rezistencija na glikopeptide, za Enterobacteriaceaena cefalosporine treće genегасije i karbapeneme, dok se za Pseudomonasspp. i Acineto bacterspp. određuje rezistencija na karbapeneme.

Za popunjavanje upitnika korišteno je više izvora podataka: temperaturne liste pacijenata, istorije bolesti, mikrobiološki i drugi nalazi, sagledavanje stanja pacijenata i konsultacije sa odjeljenskim ljekarima. Za postavljanje dijagnoze IHI je bio zadužen odjeljenski ljekar bolnice, zajedno sa epidemiologon ekipe za prikupljanje podataka.

U studiju su uključeni svi pacijenti hospitalizovani na hirurškim klinikama UKC RS na dan izwođenja studije, tj. svi pacijenti koji su primljeni na kliniku prije ili u 8 h ujutro i nisu otpušsteni u toku izvođenja studije. U studiju se uključuju i pacijenti koji su privremeno odsutni sa klinike u vrijeme izwođenja studije, zbog dijagnostičke ili terapijske procedure na nekon drugon odjeljenju,kao i pacijenti koji se otpuštaju kući na nekoliko sati u toku dana ili preko vikenda. Iz studije se isključuju pacijenti koji su primljeni samo na jedan dan (dnevne bolnice, hitne službe, pacijenti na dijalizi, pacijenti primljeni na tretman ili hiruř̌ku intervenciju koja se završava u istom danu).

Prikupljanje podataka u studiji se organizuje tako da jedna klinika/odjeljenje bude završena za jedan dan. Studija u jednoj bolnici se završava za jednu nedjelju.

Prikupljeni podaci su uneseni u odgovarajuću bazu podataka, specijalno pripremljenu za studiju prevalencije intrahospitalnih infekcija (HelicsWin.Net), a zatim analizirani ponoću odgowarajućih statističkih metoda.

\section{Rezultati}

Studijon je obuhvaćeno 196 pacijenata hospitalizowanih u vrijeme izvođenja studije na hirurškim klinikama UKC RS koji su zadovoljavali parametre za uključivanje u studiju. Od ukupnog broja pacijenata, 85 su žene $(43,4 \%)$, a 111 muskarci $(56,6 \%)$, tako da odnos polova pacijenata uključenih u studiju iznosi o,77:1 u korist muškaraca. Većina pacijenata (52,0\%) pripadala je dobnoj grupi 60-79 godina (Tabela 1.).

Tabela 1: Distribucija pacijenata prema dobi i polu

\begin{tabular}{ccccccc}
\hline Uzrast & $\begin{array}{c}\text { Broj } \\
\text { žena }\end{array}$ & $\begin{array}{c}\text { Procenat } \\
\text { žena }\end{array}$ & $\begin{array}{c}\text { Broj } \\
\text { muškaraca }\end{array}$ & $\begin{array}{c}\text { Procenat } \\
\text { muškaraca }\end{array}$ & Ukupno & Procenat \\
\hline 12-23 mjeseca & 0 & $0 \%$ & 2 & $1,8 \%$ & 2 & $4,0 \%$ \\
\hline 2-19 godina & 4 & $4,7 \%$ & 4 & $3,6 \%$ & 8 & $7,7 \%$ \\
\hline 20-39 godina & 4 & $4,7 \%$ & 11 & $9,9 \%$ & 15 & $25,5 \%$ \\
\hline 40-59 godina & 22 & $25,9 \%$ & 28 & $25,2 \%$ & 50 & $52,0 \%$ \\
\hline $60-79$ godina & 43 & $50,6 \%$ & 59 & $53,2 \%$ & 102 & $9,7 \%$ \\
\hline Uk0 godina & 12 & $14,1 \%$ & 7 & $6,3 \%$ & 19 & $100 \%$
\end{tabular}


Najveći procenat pacijenata je bio smješten u Klinici za abdominalnu hirurgiju $(20,4 \%)$ i Klinici za urologiju $(16,3 \%)$, Tabela 2.

Tabela 2: Distribucija pacijenata prema klinikama

\begin{tabular}{cc}
\hline Klinika & Broj pacijenata \\
\hline Klinika za opštu i abdominalnu hirurgiju & 40 \\
\hline Klinika za urologiju & 32 \\
\hline Klinika za ortopediju & 22 \\
\hline Klinika za traumatologiju & 15 \\
\hline Klinika za vaskularnu hirurgiju & 17 \\
\hline Klinika za dječiju hirurgiju & 17 \\
\hline Klinika za plastično rekonstruktivnu hirurgiju & 7 \\
\hline Klinika za anesteziju i intenzivno liječenje (hirurška) & 12 \\
\hline Klinika za neurohirurgiju & 8 \\
\hline Ulinika za maksilofacijalnu hirurgiju & 20 \\
\hline
\end{tabular}

Od ukupno 196 pacijenata, sedam pacijenata $(3,6 \%)$ je, prema McCabe skorı, klasifikovano u kategoriju oboljelih od rapidno letalne bolesti (bolest sa očekivanim prežvijavanjem kraćin od jedne godine). Letalnu bolest (očekivano preživljavanje ispod pet godina) su inala 32 pacijenta (16,3\%), bolest bez očekivanog letalnog ishoda (očekivano preživljavanje duže od pet godina) 138 pacijenata $(70,4 \%)$, dok za 19 pacijenata $(9,7 \%)$ nije bilo moguće definisati MeCabe skor.

U toku aktuelne hospitalizacije operisano je 139 pacijenata $(70,9 \%)$. Njih $121(61,7 \%)$ je imalo NHSN operaciju, dok je 18 pacijenata $(9,2 \%)$ imalo minimalno invazivпu(nе-NHSN) орегасіju.

Učestalost relevantnih invazivnih procedura kod pacijenata u vrijeme izođenja studije je bila sljedeća: periferni vaskularni kateter je inalo 158 pacijenata $(80,6 \%)$, centralni vaskularni kateter je imalo 15 pacijenta $(7,7 \%)$, urinarni kateter je imalo 78 pacijenata $(39,8 \%)$, dok su tri pacijenta bila intubirana $(1,5 \%)$.

Od 196 pacijenata uključenih u studiju, njih 23 je imalo aktivnu IHI tako da prevalencija pacijenata sa IHI iznosi $11,7 \%(95 \% \mathrm{CI}=7,23-16,24)$, jednako kao i prevalencija IHI.
Od ukupno 23 infekcije, devet je bilo prisutno na prijemu (39,1\%). Osam od navedenih devet infekcija je bilo stečeno u prethodnoj hospitalizaciji u istoj bolnici $(88,9 \%$ ), dok je jedna infekcija imala porijeklo u drugoj bolnici.

Najviša prevalencija IHI je zabilježena u dobnoj grupi 60 do 79 godina (Slika 1.).

Slika 1.Prevalencija intrahospitalnih infekcija prema dobnim grupama

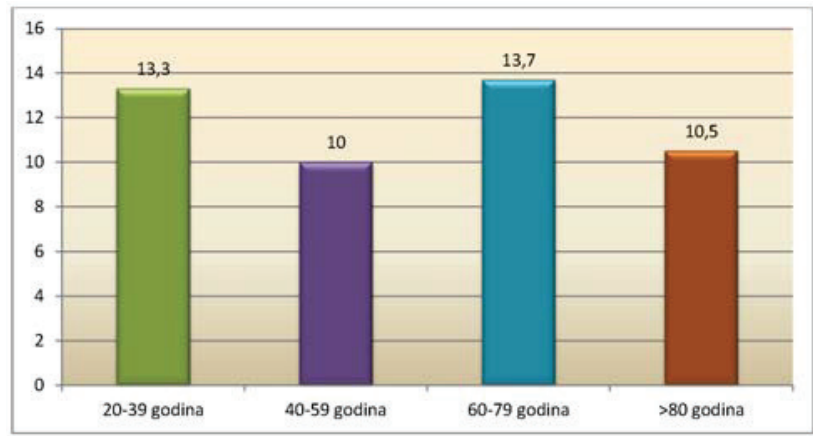

Većina pacijenata sa IHI bila je muškog pola $(69,6 \%)$. Posmatrano prema specijalnosti klinike, najveću prevalenciju $\operatorname{IHI}(37,5 \%)$ imala je Klinika za anesteziju i intenzivno liječenje (Slika 2.). 
Slika 2. Prevalencija intrahospitalnih infekcija prema specijalnosti klinika

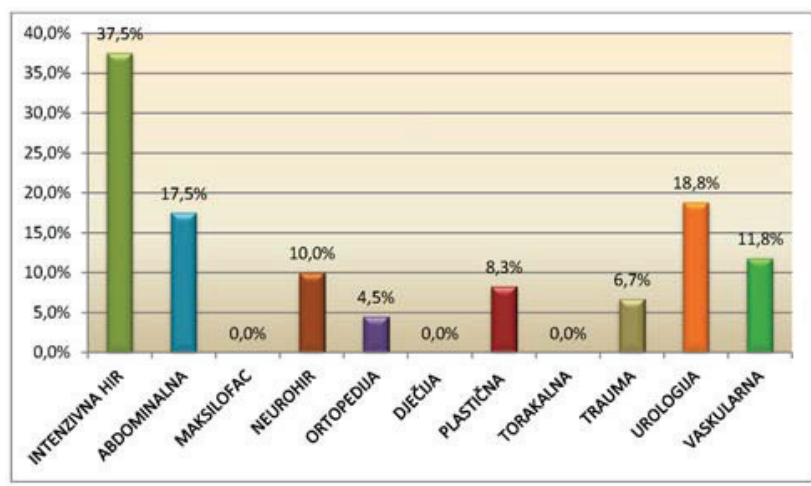

Najučestalije IHI su bile infekcije operativnog mjesta, koje su činile 60,8\%od ukupno registrowanih IHI (15/23). Polovina ovih infekcija su duboke infekcije operativnog mjesta $(30,4 \%)$. Površne infekcije operativnog mjesta čine 8,7\%, a infekcije operativnog mjesta sa zahvatanjem organa/tjelesnih šupljina $21,7 \%$ od ukupnih IHI. Pneumonije i infekcije gastrointestinalnog sistema su registrovane kod po dva pacijenta (po 8,7\%). Ostale registrowane infekcije su zabilježene kod po jednog pacijenta (po 4,3\%): infekcija centralnog nervnog sistema, infekcija kardiovaskularnog sistema, bronhitis i infekcija игіпа гnog trakta.

Od ukupno 23 IHI, 11 je imalo mikrobiološku potvrdu u vrijeme provodenja studije $(47,8 \%)$. Ukupno je izolovano 15 uzročnika: kod dvije infekcije izolowana su po tri uzročnika, dok je kod ostalił izolovan po jedan uzročnik. Najčešce izolovani uzročnici su Acinetobacterspp., Enterococcusspp., Pseudomonas aerouginosa i Staphylococcusaureus (po dva izolata tj. po 13,3\% od ukupnog broja izolowanih uzročnika). Po jednom uzročniku su izolowani Acinetobacterbaumanii, Clostridiumdifficile, Escherichia coli, Klebsiella spp., Proteus mirabilis, Proteus vulgaris i Staphylococcus epidermidis.

Test na antimikrobnu rezistenciju je na dan studije bio raspoloživ za $86,7 \%(13 / 15)$ izolovanih uzročnika IHI. Rezistencija na meticilin je zabilježena kod jednog od dva izolowana Staphylococcus aureus-a, na vankomicin kod jednog od dva izolovana Enterococcusspp., na cefalosporine treće generacije kod 40,0\% Enterobacteriaceae(2/5), dok je rezistencija na karbapeneme zabilježena kod svih izolowanih Acinetobactera (3) te kod jednog od dva izolovana Pseudomonas-a.

\section{Diskusija}

Epidemiološki nadzor nad IHI podrazumijeva sistematsko prikupljanje, analiziranje i tumačenje podataka o IHI, kao i dostavljanje povratne informacije osoblju zdravstvene ustanove u kojoj se nadzor sprovodi. ${ }^{12}$ Svjetska zdravstvena organizacija je 1981. godine preporučila sprovodenje studija prevalencijekao metod izbora za sagledavanje učestalosti IHI na nacionalnom i internacionalnom nivou. Studije prevalencije se posebno preporučuju za zemlje sa smanjenim resursima, mada mnoge razvijene zemlje izvode nacionalne studije prevalencijesvake ili svakih nekoliko godina, jer se na taj način vrši edukacija zdravstvenog osoblja i povećava motivacija za rad na problemu IHI. ${ }^{2}$

Prema rezultatima naše studije, prevalencija IHI na hirurškin klinikana UKC RS je iznosila $11,7 \%$, koliko je iznosila i prevalencija pacijenata sa IHI, što je u okvirima visine prevalencije u zenljama u razoju. Naši podaci pokazuju nižu učestalost IHI od podataka dobijenih u studiji prevalencije sprovedenoj 2000. godine, kada je prevalencija IHI na hirurškim klinikama KC Banja Luka iznosila $18,4 \%$, dok je prevalencija pacijenata sa IHI iznosila $16,1 \% .{ }^{13}$

Studija prevalencije sprovedena u bolnicama u Evropskoj uniji 2011. i 2012. godine pokazalaje da prevalencija pacijenata sa IHI na hiruškim odjeljenjima iznosi oko $7 \%$. Prema rezultatima iste studije, prevalencija na hirurškim odjeljenjima u Sloweniji je 6,4\%, a u Hrvatskoj 6,3\%." Treća nacionalna studija prevalencije bolničkih infekcija u Srbiji, sprovedena 2010. godine, pokazala je da je prevalencija pacijenata sa IHI na hirurškim odjeljenjima $5,4 \% .{ }^{12}$

Posmatrano prema specijalnosti klinika, u našoj studiji je najviša prevalencija IHI zabilježena u jedinicama intenzivne njege, 37,5\% (Slika 2.). Očekivano je da su IHI паjučestalije u jedinicama intenzivne njege, s obzirom пa težinu kliničke slike i opšteg stanja pacijenata na ovim odjeljenjima, kao i učestalije korištenje invazivnih procedura koje predstavljaju faktor rizika za nastajanje IHI, itd. Prevalencija IHI u jedinicama intenzivne njege u Evropskoj uniji iznosi 19,5\% (u Hrvatskoj 19,5\%, u Slove-

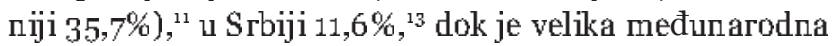
studija prevalencije, sprovedena 2007 . godine u jedinicama intenzivne njege u 75 zemalja, pokazala da je prevalencija pacijenata sa infekcijon čak $51 \% .{ }^{13}$

U našoj studiji, Klinika za urologiju bila je na drugon mjestu po učestalosti $\operatorname{IHI}(18,8 \%)$, a potom slijedi Klinika za abdominalnu hirurgiju (17,5\%). Sa druge strane, па klinikama za maksilofacijalnu, pedijatrijsku i torakalnu hirurgiju nisu za bilježene IHI (Slika 2.). 
Prema anatomskoj lokalizaciji, najučestalije IHI su bile infekcije operativnog mjesta $(60,8 \%)$. Njihova prevalencija je iznosila $7,1 \%$. Većinom se radilo o dubokim infekcijama operativnog mjesta te infekcijama operativnog mjesta sa zahvatanjem organa. Ovaj rezultat je u skladu sa rezultatima većine studija sprovedenih na hirurškim odjeljenjima,koje pokazuju da su infekcije operativnog mjesta najučestalija komplikacija kod operisanih pacijenata, ${ }^{11,12}$ uprkos činjenici da spadaju u grupu IHI koje se u najvećoj mjeri mogu prevenirati postojećim strategijama. ${ }^{13}$ Infekcije operativnog mjesta su najčešce IHI u zemljama niskog i srednjeg nacionalnog dohotka, sa incidencijom od 1,2 do 23,6 na 100 operacija. Nasuprot tome, učestalost ovih infekcija u razvijenim zemljama varira između $1,2 \%$ i $5,2 \% .7$

Infekcije operativnog mjesta su se u našoj studiji značajno čeśce javljale kod pacijenata oboljelih od letalne bolesti prema McCabe skoru.

Karakterističan rezultat u našoj studiji je niska prevalencija urinarnih infekcija (o,5\%), za razliku od većine dostupnih podataka iz mnogih zemalja, gdje su urinarne infekcije međı najučestalijim IHI. ${ }^{11,12} \mathrm{~S}$ obzirom na činjenicu da je urinarni kateter, kao faktor rizika za nastanak uгinarne infekcije, u momentu provođenja studije inalo skoro $40 \%$ pacijenata, učestalost urinarnih infekcija je vjerovatno veća nego što to pokazuju naši rezultati. Razlog za nisku prevalenciju urinarnih infekcija u našoj stıdiji je nedostatak laboratorijskih nalaza kod uključenih pacijenata koji su, prema definiciji slıčaja, neophodni za dijagnozu urinarne infekcije (minimalno je potreban nalaz sedimenta urina za dijagnozu bakteriološki nepotvrđene uгinarne infekcije).

Navedeni rezultat govori u prilog mogıćnosti da je ukupna prevalencija IHI na hirurškim klinikama UKC RS viša nego što to pokazuju podaci dobijeni u našoj studiji.

Neke od evropskih zemalja koje su koristile ECDC protokol za studiju prevalencije, a naročito zemlje sa niskim resursima, takođe su prijavljivale nedostatak laboratorijskih testova neophodnih za dijagnozu pojedinih IHI. ${ }^{11}$ Niska senzitivnost (lažno negativni rezultat) predstavlja čest problem u nacionalnim sistemima nadzora nad IHI. $^{13}$

Naša studija je pokazala da su se IHI najviše javljale kod pacijenata u dobnoj grupi 60-79 godina (prevalencija 13,7\%), a zatim u dobnoj grupi 20-39 godina (prevalencija13,3\%), Slika 1. IHI su se značajno češce javljale kod muškaraca. Prema literaturi, dob preko 65 godina i muški pol su prepoznati kao faktor rizika za nastajanje IHI. ${ }^{711}$
U momentu provodenja studije, mikrobiološku potvrdu je imalo $47,8 \%$ intrahospitalnih infekcija. Najčešći uzročnici intrahospitalnih infekcija su Acinetobacterspp., Enterococcusspp., Pseudomonasaeruginosa i staphylococcus aureus. Bakterijski uzročnici izolovani u našoj studiji su bili najčešći uzročnici IHI i u mnogim drugim studijama, s tim da je njihow redoslijed bio manje ili više izmijenjen. ${ }^{11,12 .}$

Najčešce izolovani uzročnici u našoj studiji su u visokom postotku bili rezistentni na antibiotike: rezistencija пa meticilin je zabilježena kod jednog od dva izolovana Staphylococcusaureus-a, na vankomicin kod jednog od dva izolovana Enterococcusspp., na cefalosporine treće generacije kod 40,0\% Enterobacteriaceae (2/5), dok je rezistencija na karbapeneme zabilježena kod svih izolovanih Acinetobactera (3) te kod jednog od dva izolovana Pseudomonas-a.

U Evropskoj uniji je rezistencija na karbapeneme zabilježena kod $81,2 \%$ izolovanih sojeva Acinetobacterspp. i 31,8\% sojeva Pseudomonasaeruginosa, rezistencija na vankomicinkod 10,2\% enterokoka, a na meticilin kod $41,2 \%$ izolata Staphylococcusaureus."

Treća nacionalna studija bolničkił infekcija u Srbiji je pokazala da je na karbapeneme rezistentno 30,3\% izolovanih sojeva Acinetobacter i 24\% sojeva Pseudomonas aeruginosa, na meticilin $51 \%$ izolovanog Staphylococcus aureus, a na vankomicin $9 \%$ Enterococcusspp. ${ }^{12,13}$

Rezultati dobijeni u našoj studiji prevalencije ukazuju na činjenicu da su IHI jedan od vodećih javnozdravstvenih problema kojem se mora pokloniti posebna pažnja, a metod izbora za nadzor nad IHI ná nacionalnom nivou bi mogle da budu upravo studije prevalencije. Korištenje metodologije i definicija slučaja ECDC-a bi omogućilo poređenje podataka sa drugim evropskim zemljama, te poređenje podataka izmedu bolnica i u različitim vremenskim periodima.

\section{Zaključak}

Rezultati studije su pokazali da je prevalencija IHI na hirurškim klinikama UKC RS u okvirima prevalencije u zemljama u razvoju. Problemu IHI se mora posvetiti veća pažnja. Studije prevalencije bi mogle da budu metod izbora za nadzor nad IHI na nacionalnom nivou.

\section{Reference}

1. Prevention of Hospital-aquired Infections. A Practical Guide. 2nd edition. Geneva: World Health Organization, Department of Commuicable Disease, Surveillance and Response; 2002. 
Available from: http//www.who.int/crs/resources/publications/ whocdsesrepheoo212.pdf

2. Chen $Y$, Chou $Y$, Chou P. Impact of nosocomial infection on cost of illness and length of stay in intensive care umits. Infect Control Hosp Epidemiol. 2005 Mar; $26(3)+281-287$. http $/ / \mathrm{dx}$. doi.org/10.1086/502540 PMid:15796281

3. Bailey T, Ries N. Legal issues in patient safety: the example of nosocomial infection. Healthe Q. 2005 Oct; 8(Special):140-145. http://dx.doi.org/10.12927/heq.2005.17680 PMid:16334088

4. Gilbert G, Cheung P, Kerridge I. Infection control, ethics and accountability. Med J Aust 2009 . 2009 June; 190(12):696698.

5.

Sheng WH, Chie WC, Chen YC, Hung CC, Wang YT, Chang SC. Impact of nosocomial infections on medical costs, hospital stay, and outcome in hospitalized patients. J Formos Med Assoc. 2005 May $104(5) \div 318-326$. PWid:15959598

6. World Health Organisation. Patient Safety. [Online]. [cited 2014 October 14]. Available from: http//www.who.int/gpse/ country_work/gpsc_ccise_fact_sheet_en.pdf

7. Report on the burden of endemic health care-associated infection: clean care is safer care. A systematic review of the literature. Geneva: World Health Organisation, Patient Safety: 2011. Available from: http:/whqlibdoc.who.int/publications/2011/9789241501507_eng.pdf

8. National Nosocomial Infections Surveillance System (NNISS). National Nosocomial Infections Surveillance Sygtem Report, data summary from January 1992 through Jume 2004. Am J Infect Control. 2004 Oct $32(8) 470-485$ http//dx.doi.org/10.1016/j.ajic.2004.10.001 PMid:15573054

9. Gastmeier P, Sohr D, Forster D, Schulgen G, Schumacher M, Daschner $F$, et al. Identifying outliers of antibiotic usage in prevalence studies on nosocomial infections. Infect Control Hosp Epidemiol. 2000 May; 21 (5) $524-328$. http//dx.doi. org/10.1086/501764 PMid:10823565

10. Klevens RM, Edwards JR, Richards CL Jr, Horan TC, Gaynes RP, Pollock DA, et al. Estimating health care-associated infections and deaths in U.S. hospitals, 20o2. Public Health Rep. 2007 Mar-Apr; 122(2):160-166. PMid:17357358 PMCid:PMC 1820440

11. Point prevalence survey of healthcare associated infections and antimicrobial use in European acute care hospitals - protocol version 4.3. Stockholm: European Centre for Disease Prevention and Controls 2012 .

12. Treća nacionalna studija prevalencije bolničkih infekcija 2010 . Beograd: Ministarstvo zdravlja Republike Srbije, Republička stručna komisija za nadzor nad bolničkim infekcijama, Institut za javno zdravlje Srbije; 2012.

13. Bojanić J. Epidemiološka studija bolničkih urinarnih infekcija u hirurkik bolesnika. Magistarski rad. 2001. 


\section{Prevalence of Healthcare-Associated Infections in Surgical Clinics of the University Clinical Centre of the Republic Of Srpska}

\section{ABSTRACT}

Introduction. Healthcare-associated infections (HAl) are a global public health problem that exists in all health care systems and lead to very significant consequences. All health care systems are obliged to continuously improve preventive measures, which can reduce occurrence of $\mathrm{HAl}$ by 10 to 70 percent. First step in improving prevention is constitution of functional epidemiological surveillance over HAl.

Aim of the study.The objective of this study was to show, through the point prevalence survey, the rates of HAl in surgical clinics of the University Clinical Centre of the Republic of Srpska (UCC RS), their most important epidemiological characteristics, the most frequently isolated microorganisms and their resistance to antibiotics.

Material and methods. In this study, we used standardized methodology for the point prevalence survey of HAl and antimicrobial use, including case definitions established by the European Centre for Disease Control (ECDC). The study was conducted in October 2014 at the surgical clinics of the UCC RS, and it included a total of 196 patients.

Results. The prevalence of HAI at the surgical clinics of the UCC RS was $11.7 \%$. The most common localization of HAI were surgical site infections (60.8\%). The most common isolated microorganisms were Acinetobacter spp., Enterococcus spp., Pseudomonas aeruginosa i Staphylococcus aureus. All isolated Acinetobacter and 50\% ofisolated Pseudomonas were resistant to carbapenems, 50\% of Staphylococcus aureus to methicillin, 50\% Enterococcus spp. to vancomycin, and $40 \%$ Enterobacteriaceaeto cephalosporins, 3rd generation.

Conclusion. The prevalence of HAI at the surgical clinics of the UCC RS is within the frame of the prevalence in developing countries. More attention must be given to this problem. The prevalence study may be the method of choice for HAl surveillanceat national level.

Key words: prevalence, hospital acquired infections, epidemiological surveillance 